\title{
Post Birth Challenges among Working Mothers in a Higher Educational Institute in Ghana: Implications for Occupational Competitiveness of Working Mothers
}

\author{
Suad Ahmed Salihs ${ }^{1}$, John Boulard Forkuor ${ }^{2}$, Vivian Etsiapa Boamah ${ }^{2}$ \\ ${ }^{1}$ University of Cape Coast, Ghana \\ ${ }^{2}$ Kwame Nkrumah University of Science and Technology (KNUST), Ghana \\ Correspondence: John Boulard Forkuor, Kwame Nkrumah University of Science and Technology (KNUST), Ghana.
}

Received: September 11, 2019

Accepted: October 8, $2019 \quad$ Available online: October 25, 2019

doi:10.11114/ijsss.v7i6.4516

URL: https://doi.org/10.11114/ijsss.v7i6.4516

\begin{abstract}
In Ghana, most formal employment opportunities require employees to work for 8 hours for 5 consecutive days each week. While this may not be challenging to men in the socio-cultural context of Ghana, the socio-cultural expectation of women as carers and home keepers sometimes make this requirement of formal occupations difficult for some women. Of all the challenges facing women in formal occupations in Ghana, one of the least explored is the implication of post birth depression on the productivity of women within the formal sector in Ghana. This paper presents data from an exploratory qualitative research that used qualitative interviews to explore the post birth mental health challenges of working mothers within a public university in Ghana. The paper reveals that working mothers suffer stress, frustration and self-esteem challenges and that these challenges have implications for the occupational wellbeing of women in higher educational institutions. While these challenges are similar for women in other occupational fields, our argument is for higher educational institutions to consider the real and present implications that these challenges have for the occupational progress of working mothers.
\end{abstract}

Keywords: post birth depression, working mothers, women in occupations

\section{Introduction}

Segregation based on gender is common in the labour force globally (Busch, 2011). Occupational based gender segregation may be distinguished based on sector of employment; under representation of a particular group within a specific occupational sector; or in terms of the under representation of a particular group within positions of power and authority (Bettio \& Verashchagina, 2009). While some authors argue that gender based segregation is a direct result of social inequalities between the sexes, others argue that the segregation is rather the cause of existing and persisting inequalities between the sexes (Pratto et al., 1997). Although several studies has been conducted on gender based segregation (Abukari \& Odai, 2018; Busch, 2011; Evans, 1997; Lowson \& Arber, 2014; Worthington, Esposito, Nieri, \& Glenny, 2003), what is known is that a variety of factors contribute to its persistence and that it has implications for discrimination based on pay and promotions. One of the key factors that has been highlighted as having a continuous impact on gender based segregation is the demand for shorter and flexible hours of work as a result of the unequal burden of care between men and women (Bettio \& Verashchagina, 2009). According to research by Tower (2008) mothers in the workforce are doubly burdened by social traditions that expect women to meet male gender standards at the work places as well as conform to the traditional female gender role of being nurturance. This expectation comes with a social cost, including the high incidence of single or divorced working mothers; and the increasing pressure some women feel to choose between having children or enhance their occupation. For other women, the alternative is to engage in an economic activity within the broader informal economy (Chant \& Pedwell, 2008). In developing countries like Africa, while privatisation and the increasing role of private stakeholders has provided increasing employment opportunities for both men and women, private enterprises in Africa have not paid adequate attention to child care and social welfare benefits as a relevant aspect of employment conditions (Brumley, 2014). On the contrary, private and state organisations increasingly demand employee attitudes that emphasise work over family. For most women who have to combine domestic responsibilities with work, this characteristic of formal employment has had negative implications for their career mobility (Brumley, 2014). Some organisations go to the extent of actively seeking either male employees or 
unmarried female employees as a result of their emphasis on economic competitiveness compared to family and social ties (Brumley, 2014).

In Africa in general, traditional norms and values and social expectations regarding what men and women must and should do is a key determinant of occupational choices among men and women on the continent (Abukari \& Odai, 2018; Barker \& Ricardo, 2005; Forkuor, 2016; Forkuor, Buari, \& Aheto, 2019). While some men and women are gradually crossing into occupational sectors that have previously been dominated by one gender (Forkuor, 2016; Forkuor et al., 2019; Overa, 2007), occupational gender segregation is still very high on the African continent. In Ghana, most formal employment opportunities require employees to work for 8 hours for 5 consecutive days each week. While this may not be challenging to men in the socio-cultural context of Ghana, the socio-cultural expectation of women as carers and home keepers sometimes make this requirement of formal occupations difficult for some women (Krakah et al., 2015). Available research indicates that a number of women in Ghana's urban areas willingly seek occupations in the informal economy, in order to take advantage of the flexibility that informality present; earn a decent income and still meet socio-cultural expectations of women (Anyidoho et al., 2016). For those women who choose to remain in formal sector occupations, a combination of these challenges hinders their progress and development. For instance, very few women are in top managerial positions in Ghana. The few women who find themselves in these positions often work in relatively smaller and localized organizations. In addition to career progress, other challenges faced by women are differences in pay between men and women who occupy the same positions and have similar expectations (Pratto et al., 1997). The possibility of labour market discrimination, the concept of "glass ceiling", and a possible incidence of post-birth depression (a mood disorder that affects women after childbirth) cannot be completely ruled out for the differential occupational progress between men and women.

Of all the challenges facing women in formal occupations in Ghana, one of the least explored is the implication of post birth depression on the productivity of women within the formal sector in Ghana (Anokye, Acheampong, Budu-Ainooson, Obeng, \& Akwasi, 2018; Guo et al., 2013; Scorza, Owusu-Agyei, Asampong, \& Wainberg, 2015). A combination of factors, including a contextual assumption that child birth must be accompanied with joy, happiness and thanksgiving, have ensured that any perceived negative conversation (including conversation about mental health challenges of mothers) are discouraged. Consequently, while mothers have failed to discuss it, the phenomenon has also failed to gain the needed attention among researchers, social workers, public health experts and other relevant stakeholders (Anokye et al., 2018; Weobong et al., 2015). Most importantly, gender activists in Ghana have not adequately explored how this health challenge must be incorporated in measuring or evaluating the productivity of working mothers within the formal sector. Most of the emphasis among gender activists has been on political representation of women in the Ghanaian political sphere in general (Madsen, 2019; Tsikata, 2009). Thus, quantitative performance indicators, that does not take into consideration post-birth challenges risk perpetuating the erroneous assumption that men perform better under all circumstances in formal occupations. Furthermore, the nationwide desire to get more women into leadership positions (Madsen, 2019; Tsikata, 2009) in organizations may not be achieved if the mental health challenges of working mothers are not adequately discussed and addressed.

This paper seeks to begin stakeholder discussions on post birth depression and its implication for the occupational wellbeing of women in Ghana. For the authors of this paper, this is important since the findings present a different approach towards promoting the occupational wellbeing of women. We begin with the assumption that post birth depression is a major factor that hinders the competitiveness of female academics. Thus, failure of university authorities to consider this challenge of working mothers in determining promotion requirements could potentially perpetuate the limited number of Female Academic Mothers (FAM) in higher positions within academia in Ghana. This paper presents data from a research that used qualitative interviews to explore the post birth mental health challenges of working mothers within a public university in Ghana.

\section{Methods}

\subsection{Area of Study}

This exploratory qualitative research was conducted at the Kwame Nkrumah University Science and Technology (KNUST), Kumasi. The choice of this institution was made based on the institution's relevant characteristic as a public university, as well as its convenience to the authors of this article. The first author worked as an intern at the university during the period of data collection and the second and third authors supervised her work, data collection and analysis and write-up.

\subsection{Sampling}

The target population was female employees of the university who had gone through pregnancy and/or child birth before. Purposive and snowball sampling techniques were used to select respondents. Purposive sampling was used to select respondents who fit the following criteria: (a) mother, (b) working in the formal sector and/or (c) pregnant during 
occupation. The respondents selected met criteria (b) and either criteria (a) or criteria (c) in addition. The first respondent was purposively selected based on the criteria above. While purposive sampling proved useful, only a few respondents could be identified through this approach since the researchers, at the time of the research did not have access to the list of female employees who fit the criteria specified above. The use of snow ball sampling therefore proved relevant in identifying other respondents for the study. Thus, after the first three respondents were purposively selected, the remaining respondents were selected through snowballing. A total of 13 respondents were involved in this study. Numerous factors, including financial resources, time available to researchers, availability of respondents, determined the number of respondents included in this exploratory study.

\subsection{Data Collection}

Semi-structured interviews were conducted with respondents. All interviews were conducted in the offices of respondents and lasted for an average of 30 minutes each. Each interview was conducted in the English language since English is the official language of communication, and instruction at all institutions of education in Ghana. Thus, all respondents were familiar and comfortable with the English language as the mode of communication for this interview. Researchers developed and used a semi-structured interview guide for this study. The questions that constituted the interview guide were derived from the research objectives. However, in the course of each interview, the researcher followed up on information that emerged as part of the interview but was not necessarily on the interview guide. This flexibility allowed for a broader and more in-depth exploration of the research questions. Thus, researchers used this qualitative data collection tool in order to give the respondents the freedom to express their experiences and views. As the data collection progressed, researchers modified the interview guide to include themes that emerged from previous interviews but were not included in the interview guide initially developed. All interviews were audio recorded.

\subsection{Ethical Considerations}

Researchers provided all respondents necessary for them to give consent prior to data collection. Specifically, researchers informed respondents about the nature and purpose of the research, what was required of them (in terms of time and information), and the anticipated time each interview will take. In addition, researchers sought consent of respondents to audio record the interview and assured respondents that their identities will remain anonymous both in terms of data storage as well as in publications and reports. All respondents allowed researchers to audio tape the interviews.

\subsection{Data Analysis}

Manual content issue-focused analysis, as explained by Seidman (2013) and Weiss (1994) was used to analyse the data. Specifically, analysis for this study began with transcription of qualitative data. After the transcription of data, thematic analysis was conducted on the transcribed data. Since there were specific research questions informing this paper, the transcripts were re-organized under relevant research questions. After this initial organization, relevant codes were identified. After coding, the third step was to search for themes. Researchers looked for codes which could be put together and also can capture something significant about the research question. The identified themes under each research question were subsequently reviewed to ensure that the themes accurately reflected the meanings in the data and addressed the specific research question. The themes were further explored to identify inter-linkages and how they fit together in addressing the research questions of interest. The review also explored how specific themes complemented or challenged other themes in presenting a holistic understanding and response to the guiding research questions. The interlink-ages among the themes were used to enhance the presentation of results, ensuring a presentation of results that is non-repetitive and concise.

\section{Results}

The results are presented narratively using the two key research questions as organising categories: (a) Which challenges do working mothers encounter post childbirth? (b) Which coping strategies did working mothers adopt to deal with post birth challenges? In presenting the results of each research question, the main themes that emerged from the analysis are used as subheadings to help the reader understand the developing narrative. The real names of respondents have also been replaced by pseudonyms, in the form of abbreviations (MA; MF etc) to ensure the anonymity of respondents.

\subsection{Which Challenges Do Working Mothers Encounter Post Childbirth?}

The analysis of the responses to this question revealed frustration and stress as two of the main challenges working mothers face after childbirth. These two challenges are presented and discussed below.

\subsubsection{Frustration: A Working Mother's Challenge}

The respondents indicated that right after three months of giving birth they returned to work and that the process of transitioning to work after child birth was not always smooth. Respondents who lived very far away from their families 
were particularly challenged in this regard. During this period, the respondents indicated that they had to rush to finish all their chores at home including child caring; then rush to work and while at work, they rushed to finish their work in order to return home to their babies: “........ When I started work, there was no breast pump because it was scarce. So, I closed at 1pm then rush home to breast feed the baby. So, you will be closing at lpm for one year when you resume.... you rush home to do your house hold chores and attend to your baby (AT)". For other respondents, the main challenge was with transitioning from taking care of a child on a full time basis, to doing so only part of the time, especially regarding the different psychological demands of child care and their job. MF for instance explains: "....I don't know if it happens to all mothers or if it's just me but when I am taking care of a baby and there is the need for me to do something related to my employed work, I find it difficult switching my brain back to work mood...it was always very difficult. It took me a while to get adjusted to it". MF further added that, "... when I have to work, switching back into work mood was difficult. So, I spent more time especially when it comes to writing, you know most of our work is research so you have to sit down and analyse data and come to conclusions". In her response to this question, ST recollected her struggles; trying to fully concentrate on work and at the same time having a desire to be with her child. ST explained that resuming work was challenging because: "I wanted to be with my daughter anytime she cries". Here, ST demonstrates some form of anxiety, especially when she has to be separated from her child for work reasons. The results above clearly indicates the challenges that mothers go through in regaining the 'work ethic' or 'work orientation' required for success on their job. This finding may have important implications for the overall success of employed mothers in academia, especially in terms of promotion.

In addition to the concerns raised above, the frustration experienced by working mothers extended to restrictions in their choice of clothing and opportunities to attend social events. In her narrative, MA explained that having a baby requires lifestyle changes from mothers, some of which negatively affects their engagement in social activities:

...you know once you have your baby you can't do the things that you used to do. I mean you can't go out to see your friends; you're restricted in your outfit because you can't wear what you want to wear. Me, I used to like wearing high heels a lot but after my baby I couldn't wear them because you won't be comfortable enough to carry him. I also like white dresses but after having a baby, I realized it wouldn't help so I changed some of my dresses because if I wear light coloured dress, child care will stain it.

For MF, the challenges to her social life went beyond attending weddings and wearing clothing of her choice to include challenges in her ability to socialise and enjoy dates with her husband. She explains:

"...I used to go out with my husband a lot. But after the baby came, those outings stopped because we had to be home for the baby. I guess we could start that again but we already talked about it, but it is difficult since we both don't want other people coming in to help. So in this case, if we have to go for evening outing then someone will have to come and take care of the baby. So we haven't done that in a while".

Respondent MA reported that not being able to honor invitation to participate in social activities gradually decreased her social capital:

"I was totally restricted with social programs because there are some programs that you can't take the baby along because the baby will be tired. It got to a point where people accused me of not honoring invitation to social events, but it was not as if I did not want to go. When there is no one to take care of the baby, you have to be there, you can't leave the baby behind"

The above quotations represent the experience of most of the working mothers interviewed as part of this study. This was a major source of frustration for mothers some of whom indicated that the only social event they attended often was going to church on weekends: "It was only church that I went to, once in a while. But for other social events..., because I didn't have anyone to leave the girl with...If I have to attend, I have to go with her (ME)."

Another respondent briefly indicated the changes in physical appearance that occurs as a major source of frustration after childbirth. AS explained that pregnant women undergo drastic changes in their whole body during the entire 9 months period of carrying the baby in their womb. Closely related with the changes in physical appearance explained above is a sense of emptiness that some respondents indicated that they experienced after birth. AS explains: “...During the first four weeks, it's like you're now getting used to your body because of the heaviness that has been relieved from you. Then there comes a sense of emptiness for a while...You will be empty for some time...". Such changes in the physical body also contributes to the sense of frustration that working mothers expressed.

\subsubsection{Stress: A reality for all Working Mothers}

Respondents mentioned that the act of caring for infants is very stressful especially when they have to combine this with work. Without enough support from spouse or family members, new mothers are likely to experience baby blues. This is a mild form of the postpartum depression (PPD) which can progress to PPD when left untreated. Mothers 
experiencing baby blues feel worry, unhappiness and fatigue after having a baby. The experience of baby blues lasts for a week or two. The feeling of worry about the baby or whether mothers are doing things right with infants usually causes them to experience sleeplessness. Accordingly, almost all the respondents complained of interrupted sleep during the first few weeks or months. MJ recounted her ordeal, "...I couldn't sleep throughout the night, not even for a day because the baby won't let you be". According to MF she was so worried about the baby so she used to check on him every hour to ensure he was fine and this negatively affected her sleep and increased her stress during the day: "for sleepless night yes. Because in the beginning, I think it was out of happiness and too much joy I couldn't sleep. It was also too much worries so every hour I would go and check on him, every 2 hours I would feed and put him back to sleep". Similar to the findings above, MA also commented about her sleep challenges:

"So, the interrupted sleep wasn't easy. Because before you give birth you are able to sleep throughout the night without anyone interrupting. But when you give birth you know they cry in the night. In the night sometimes a baby can wake up for about five times and each time you will have to wake up and attend to the baby so that was a bit of challenge for me"

The feeling of unhappiness experienced by the respondents was caused by mood swings. Thus, respondents explained how they could feel very happy at one moment and then experience sadness at a moment's notice: "pregnancy creates havoc on our hormone level. I had some mood swings; one minute I would be so happy. Well, having a baby is a joyous moment for every mother. Once the baby arrives you are so happy but then the next minute you find yourself so sad and you yourself you don't know why. So, I had mood swings" (MF). Some respondents reported that the mood swings made them easily irritated but not often. AT explained that: “... It's just when it's your first time of pregnancy that some things you would like to hear or someone to say might easily irritate you". MA further explained: "....so sometimes when he starts crying, I also end up crying because I am stressed up (laughs)." She also added that, "... I used to cry a lot especially with first baby when you don't know much about baby stuff."

Thus, while working mothers are on maternity leave, they still go through significant challenges which may affect their preparedness and readiness to make a meaningful contribution on their return to work.

\subsection{What Coping Strategies Did Working Mothers Adopt to Deal With Post Birth Challenges?}

The analysis of responses revealed that for working mothers, prioritizing activities and learning to balance work and life expectations was often the most reliable way of addressing the challenges they faced post-birth. A few respondents indicated spousal support as another component relevant for negotiating the post birth challenges they face.

\subsubsection{Prioritising and Balancing Work-Life Expectations}

For some respondents, personal resilience and religiosity served as an important strategy for negotiating the post birth challenges they faced, while remaining relevant at the work place. For instance, MY, in her explanation emphasized the challenges, the inner strength she had to use and the help of God as way of negotiating the challenges:

"...there are ups and downs; you know the emotional switches here and there. Yes, and you are required to deliver irrespective of your condition or whatever, because that is what you actually signed up for. So you have to bury all the weaknesses (the desire to be in bed and all the morning sicknesses), you still have to get out from bed and come to work. Yes, so it is as difficult as you can imagine it right now. But with help of God we were able to pull through."

For other respondents, conscious and unconscious ways of managing the expectations at home and at school came in handy. Respondent AT recounted:

“...it's all about planning and management. If you have stuff to attend to or work load to attend to you have to wake up early then do all your household chores. If there is someone to take care of the child, you leave the child at home or maybe you have to take the baby to a creche then you have to do that. Then you come to work, finish your work then go and pick up your baby"

Though her response above indicates personal resources and innovativeness in meeting competing demands, it also highlights reduced sleep time, as a necessary product of this approach to coping. As earlier indicated, this reduced sleep time may affect the mother's productivity during the day. For other respondents, prioritizing and managing expectations had implications on their productivity in terms of meeting deadlines and delivering outputs on time:

"I realized that I had to really prioritize in all areas. Therefore, at home I know I have to do this and that so I decide which one is more important; then I do it first by assigning time lines to do it. Therefore, I know that I have two hours at home in the morning so I do the most important things then leave the house. Then when I come to work, I know I have eight hours before I go to pick up my baby. So, I do what is most important then I leave the rest. That is what I did but the pace was very slow at the beginning but slowly I was able to get some 
work done" (MF)

Some respondents were most productive while their babies were asleep. Therefore, they plan their daily activities around the sleeping time of the baby. Others brought tasks that had to be completed at work home. MA elaborates on this in the following quotation:

“...hmm with regards to the work strategy, at times there are things that I had to do at work; if I had to do something during the day and I couldn't do it, I take it home and do it at night when the baby is asleep. It is during the night that I am able to do things that I am not able to do during the day...during the day too, there are household chores to be done because I did not want the house to be untidy. So, it's like when the baby is sleeping and I also want to sleep during the day I end up doing household chores and end up getting tired as well.

While some activities are prioritized the most or relegated to later times, other important activities that are less compelling or not mandatory like social event are forgone. Thus, as a way of coping with both the increased responsibilities of childcare and the associated stress, respondents reported not attending social gathering, hanging out with friends and their spouses.

\subsubsection{Social Support as a Coping Strategy}

Another way of coping and adapting to the increased responsibilities of working mothers was to rely on social support. Although the idea of having more help both at home and work seem easier, most respondents commented on how difficult it was to find extra help especially when the help is not from their family members. However, the presence of support at home from spouses and respondent's mothers was very important in reducing stress. MY argued:

"It all boils down to the support I was talking about. If you need help, you just have to find someone to do that for you even though you know what happens with these helps. But my mum is there, I live with my mum so anytime I am coming to work she takes care of them and when I go home too, she helps with home chores, basically cooking and taking care of them. Therefore, I am able to have some time for myself to look through my papers and prepare for lectures. However, the case will be different if you do not have that help. And that alone will bring a lot of stress on you because you will have so many things to be thinking about."

While the above quotation clearly explains the relevance of the availability of social support for working mothers, some respondents pointed out that social support was not the panacea to all the challenges they faced after birth but the presence of support served as a platform for them to adjust and negotiate the varying expectations placed on them as working mothers. In addition to the support received from family members especially parents, few respondents indicated that they received some support, albeit insufficient, from their spouses. In her narrative, AT explained the support of her husband this way:

"Yes, my husband was so helpful. He enjoys cooking and other household chores so normally when he gets to the house early, he prepares something for us to eat...but it was not enough. Therefore, my mother had to come in ... she came to help me out with that. When I delivered, my mother came and I also went to her"

Similar to AT's assertion, MF argued that the support she received from her spouse was not adequate: "well my husband helped out a bit with the household chores but he's a man so there's not so much he can do...". The preceding notwithstanding, respondents argued that they preferred having support from their parents and spouses rather than go in for a hired help. Respondents also commented on the importance of institutional support in the form of flexible work schedule, as an important support system for coping with the challenges they face after birth. Respondent MJ reported: “... the normal time is 8 but they let you come at 9 o'clock then you close at 12 o'clock for one year. Then after the one year you come to your normal time which is starting at 8 and then you close at 5 'oclock".

Thus far, the results demonstrate that working mothers try to prioritise and sacrifice social events as a way of managing the sometimes-competing requirements of being a mother and an employee. The success of this coping strategy is dependent, to an extent, on the quality of spousal and family support as well as the institutional policies and programs consciously instituted to enhance the wellbeing of the working mother.

\section{Discussion of Findings}

This research has revealed how mothers go through physical changes after birth and have to make lifestyle changes to accommodate their new status as mothers. These lifestyle changes include changes in the frequency and quality of social engagements as well as changes in physical appearance and fashion choices. Even though these changes were not explicitly linked with emotional or psychological challenges, when taken together, they portray a different image. While some may argue that the responses above present information that is common for all mothers, what has not been emphasized much in the literature is the implication of these challenges for the emotional and psychological wellbeing 
of working mothers. For instance even though respondents did not explicitly indicate; there is ample literature (Denissen, Penke, Schmitt, \& van Aken, 2008; Machin \& Jeffries, 2017; Pop, 2016; Wesselmann, Wirth, \& Bernstein, 2017) that suggests that a person's ability to engage actively in social processes, including socialization, and the quality of interaction between them and their social network (friends and family) has implications for their psychological and emotional wellbeing. The findings, with regards to fashion choices are also indicative in specific ways. For instance social psychologists have established a relationship between fashion choices (including a person's ability to feel good and be comfortable with their appearance) and self-esteem (Baron, Branscombe, \& Byrne, 2009; Denissen et al., 2008; Pop, 2016). Our argument here is that the inability of working mothers to engage meaningfully in social events and to dress in ways that they want may also affect that their emotions and their sense of self negatively.

This research has sought to re-focus attention on the psycho-emotional challenges that working mothers face after child birth. What we found is that working mothers face emotional and psychological difficulties in transitioning from being a mother to being a worker. In addition, the separation of mother from child after the maternity leave creates a sense of anxiety for mothers even at the workplace. This as has been indicated in this research, may have negative implications on the occupational performance of working mothers as compared to their female colleagues who have not necessarily gone through the same experience as well as their male colleagues. The findings also revealed that the social life and the self-esteem of working mothers are sometimes negatively affected. Sleeplessness, mood swings are all challenges that working mothers continue to face. Our thesis is that maternity leave in all its forms, on its own is not sufficient to address the real challenges that working mothers experience. Our recommendation is for the University authorities to adopt specific policies that address the psycho-emotional needs of working mothers and considers these needs in promotion requirements. For instance there are some institutions of higher learning that have sought to increase the enrolment of women in engineering and other male dominated programs by reducing the grade requirement for female applicants (Martin, 2019). While some have argued that this approach perpetuates the assumption that women cannot compete with men on the same level, proponents of this approach, including the Anti-Discriminatory Board in Australia for instance, argue that this is necessary to address the gender imbalances in male-dominated industries (Martin, 2019). A similar approach can be used to address the peculiar needs of working mothers as highlighted in this study.

\section{Recommendations}

As earlier indicated, the following recommendations are made specifically for the appointments and promotions committees of higher educational institutions in Ghana to consider, as a way of promoting equity in terms of job promotions. The recommendations are not made instructively, but rather with an aim of beginning more in-depth discussions regarding the wellbeing of women as employees in higher educational institutions.

In order to address some of the challenges highlighted in this study, including poor social engagement, negative self-esteem among others, we recommend that institutions of higher education, must of necessity, extend their support of working mothers from simply providing maternity leaves to providing conducive environment for work to proceed. This includes setting up enclosed crèche within office complexes, where working mothers can feel closer to their wards. The convenience that this approach provides working mothers may help to reduce some of the anxiety and divided attention that working mothers experience when they have to leave their wards behind for work. In addition to the above, institutional welfare efforts should extend beyond the provision of health support and support during times of grief. In this instance, higher institutions must create an avenue for working mothers to meet, socialise and share experiences. This could be a specific day, set within the academic calendar, where mothers can bring their children to the work environment and socialise with their colleagues. The relevance of this approach is to try and create an avenue for social engagement and through that reduce the sense of social isolation that some working mothers experience. Our argument is that the shared experience that this will engender will improve the mood of working mothers, which will then have positive implications on their output at the workplace.

In addition to the above, since this research has revealed gender specific challenges related to child-birth, challenges that have implications for occupational related activities; we recommend that promotions committees in higher educational institutions in Ghana must consider maternity, during the period under consideration for promotion, as a relevant factor. For instance if lecturers are expected to publish 4 manuscripts within a 4 year period in order to be promoted to the next level, we recommend that for employees who got pregnant or gave birth during that period, this expectation should be reduced to a slightly lower number of published papers, for instance 3 . For the authors, this will allow women to work, be parents and still remain competitive not only with their male colleagues but also with their female colleagues who have not had the same experience. Our argument remains that the current structure and forms of maternity leave, that was supposed to ease the pressure on working mothers, has done little to improve the competitiveness of working mothers and the representation of women in top organisational positions. We are confident that women can, and must be supported to; achieve success in the organisational space without having to sacrifice motherhood in the process. While some may argue that this approach is tokenistic and discriminatory, we argue rather 
that this recommendation is not asking authorities to promote women simply because of their biological sex. On the contrary, this recommendation is more about recognising the peculiar challenges faced by the different sexes and using it to inform specific policies and decision making procedures. This recommendation emphasises the development of gender sensitive and gender specific promotions approaches that appreciates the challenges of the various sexes, rather than relying on the existing broad based appointments requirements that assumes equal challenges and opportunities for all. Without ignoring the potential for this to be abused, we recommend that this exemption or reduced requirement must be assessed on a case by case basis and must also be optional for working mothers. In other words, working mothers who feel able to produce the same number of publications should not necessarily be restricted by this requirement.

\section{Conclusion}

The complexity of human experience means that organisations must constantly seek ways of getting the best output from their employees. While working mothers face several challenges, post birth socio-psychological challenges is one of the least explored within the Ghanaian context. This research has revealed the stress, frustration and self-esteem challenges that working mothers face and the implication of these for the occupational wellbeing of women in higher educational institutions. While these challenges are similar for women in other occupational fields, our argument is for higher educational institutions to consider the real and present implications that these challenges have for the occupational progress of working mothers. If we are to get more women into leadership positions and positions of authority in higher educational institutions, then we cannot ignore the implications of motherhood on occupational competitiveness and progress. Our recommendations above aim to start a discussion on improved ways of getting the best out of female employees in higher educational institutions.

\section{Funding}

This research received financial and logistical support from the African Research Academies for Women (ARAW).

\section{References}

Abukari, R., \& Odai, R. O. (2018). Gender and the Labour Market in Ghana: The Relationship in Terms of the Family, the Market and the State. Advances in Applied Sociology, 08(04), 285-294. https://doi.org/10.4236/aasoci.2018.84015

Anokye, R., Acheampong, E., Budu-Ainooson, A., Obeng, E. I., \& Akwasi, A. G. (2018). Prevalence of postpartum depression and interventions utilized for its management. Annals of General Psychiatry, 17(1), 1-8. https://doi.org/10.1186/s12991-018-0188-0

Anyidoho, A., Addoquaye Tagoe, C., Adjei, M., Appiah, E., Yeboah-Banin, A., Crentsil, A., ... Torvikey, D. (2016). Shakespear lives in Ghana: Roles, Representations and Perceptions of Women in Contemporary Ghanaian Society. Institute of Statistical, Social and Economy Research. Accra. Retrieved from https://www.britishcouncil.org.gh/sites/default/files/shakespeare_lives_women_in_contemporary_ghana_final_rep ort_4_april.pdf

Barker, G., \& Ricardo, C. (2005). Young men and the construction of masculinity in sub-Saharan Africa: Implications for HIV/AIDS, conflict and violence. Social Development Papers: Conflict Prevention and Reconstruction, 26, 1-81. https://doi.org/http://www-wds.worldbank.org/servlet/WDSContentServer/WDSP/IB/2005/06/23/000012009_2005 0623134235/Rendered/PDF/327120rev0PAPER0AFR0young0men0WP26.pdf

Baron, R. A., Branscombe, N. R., \& Byrne, D. (2009). Social Psychology (12th ed.). Boston: Allyn and Bacon.

Bettio, F., \& Verashchagina, A. (2009). Gender segregation in the labour market: Root causes, implications and policy responses in the EU. European Commission, Directorate -General for Employment, Social Affairs and Equal Opportunities. https://doi.org/10.2767/1063

Brumley, K. M. (2014). "Now, We Have the Same Rights as Men to Keep Our Jobs": Gendered Perceptions of Opportunity and Obstacles in a Mexican Workplace. Gender, Work and Organization, 21(3), 217-230. https://doi.org/10.1111/gwao.12031

Busch, A. (2011). Determinants of Occupational Gender Segregation: Work Values and Gender (A) Typical Occupational Preferences of Adolescents (SFB 882 Working Paper Series No. 2). Bielefield. Retrieved from https://pub.uni-bielefeld.de/download/2490164/2490165/SFB_882_WP_0002_Busch.pdf

Chant, S., \& Pedwell, C. (2008). Women, gender and the informal economy: An assessment of ILO research and suggested ways forward. Discussion Papers. Geneva. Retrieved from

https://www.ilo.org/wcmsp5/groups/public/---dgreports/---gender/documents/publication/wcms_091605.pdf

Denissen, J. J. A., Penke, L., Schmitt, D. P., \& van Aken, M. A. G. (2008). Self-Esteem Reactions to Social Interactions: 
Evidence for Sociometer Mechanisms Across Days, People, and Nations. Journal of Personality and Social Psychology, 95(1), 181-196. https://doi.org/10.1037/0022-3514.95.1.181

Evans, J. (1997). Men in nursing: Issues of gender segregation and hidden advantage. Journal of Advanced Nursing, 26(2), 226-231. https://doi.org/10.1046/j.1365-2648.1997.1997026226.x

Forkuor, J. B. (2016). Food Vending Among Men in Kumasi: Socio-Cultural Advantages, Constraints, and Coping Strategies. International Journal of Social Science Studies, 4(2), 94-102. https://doi.org/10.11114/ijsss.v4i2.1278

Forkuor, J. B., Buari, M. A., \& Aheto, C. K. A. (2019). Breaking Barriers: The Experiences of Women in Male Dominated Informal Sector Occupations in Urban Ghana. Gender Issues. https://doi.org/10.1007/s12147-019-09231-5

Guo, N., Bindt, C., Bonle, M. Te, Appiah-Poku, J., Hinz, R., Barthel, D., ... Ehrhardt, S. (2013). Association of antepartum and postpartum depression in ghanaian and ivorian womenwith febrile illness in their offspring: A prospective birth cohort study. American Journal of Epidemiology, 178(9), 1394-1402. https://doi.org/10.1093/aje/kwt142

Krakah, A., Dadson, I., Oduro-Denkyirah, A., Odoom, D., Ossei, G., Debrah, F. K., ... Adzovor, P. (2015). National employment report. Accra. Retrieved from https://statsghana.gov.gh/gssmain/fileUpload/pressrelease/NATIONALEMPLOYMENT 24-5-16.pdf

Lowson, E., \& Arber, S. (2014). Preparing, Working, Recovering: Gendered Experiences of Night Work among Women and their Families. Gender, Work and Organization, 21(3), 231-243. https://doi.org/10.1111/gwao.12032

Machin, T. M., \& Jeffries, C. H. (2017). Threat and opportunity: The impact of social inclusion and likeability on anonymous feedback, self-esteem, and belonging. Personality and Individual Differences. https://doi.org/10.1016/j.paid.2016.11.055

Madsen, D. H. (2019). Women's political representation and affirmative action in Ghana (Policy Note No. 1).

Martin, L. (2019). University lowers entry score for female applicants in male-dominated courses. Retrieved September 2, 2019 , from

https://www.theguardian.com/australia-news/2019/aug/29/university-makes-10-point-entry-score-adjustment-for-fe male-applicants

Overa, R. (2007). When men do women's work: Structural adjustment, unemployment and changing gender relations in the informal economy of Accra, Ghana. Journal of Modern African Studies, 45(4), 539-563. https://doi.org/10.1017/S0022278X0700287X

Pop, C. (2016). Self-esteem and body image perception in a sample of university students. Egitim Arastirmalari Eurasian Journal of Educational Research, 64, 31-44. https://doi.org/10.14689/ejer.2016.64.2

Pratto, F., Sidanius, J., Pratto, F., Stallworth, L. M., Sidanius, J., \& Siers, B. (1997). The Gender Gap in Occupational Role Attainment: A Social Dominance Approach The Gender Gap in Occupational Role Attainment: A Social Dominance Approach. Journal of Personality and Social Psychology, 72(February), 37-53. https://doi.org/10.1037/0022-3514.72.1.37

Scorza, P., Owusu-Agyei, S., Asampong, E., \& Wainberg, M. L. (2015). The expression of perinatal depression in rural Ghana. International Journal of Culture and Mental Health, 8(4), 370-381. https://doi.org/10.1080/17542863.2015.1037849

Seidman, I. (2013). Interviewing as qualitative research: A guide for researchers in education and the social sciences (4th ed.). New York: Teachers College Press.

Tower, L. E. (2008). The Social Costs of Career Success for Women. Review of Public Personnel Administration, 28(2), 144-165.

Tsikata, D. (2009). Affirmative action and the prospects for gender equality in Ghanaian politics. Retrieved from https://library.fes.de/pdf-files/bueros/ghana/10484.pdf

Weiss, R. S. (1994). Learning from strangers: The art and method of qualitative interview studies. New York: The Free Press.

Weobong, B., Ten Asbroek, A. H. A., Soremekun, S., Danso, S., Owusu-Agyei, S., Prince, M., \& Kirkwood, B. R. (2015). Determinants of postnatal depression in rural Ghana: Findings from the don population based cohort study. Depression and Anxiety, 32(2), 108-119. https://doi.org/10.1002/da.22218

Wesselmann, E. D., Wirth, J. H., \& Bernstein, M. J. (2017). Expectations of social inclusion and exclusion. Frontiers in 
Psychology, 8(FEB), 6-10. https://doi.org/10.3389/fpsyg.2017.00112

Worthington, H. V, Esposito, M., Nieri, M., \& Glenny, A. M. (2003). What is a systematic review? European Journal of Oral Implantology, 1(April), 174-175. https://doi.org/10.1097/00008877-200411000-00002

\section{Copyrights}

Copyright for this article is retained by the author(s), with first publication rights granted to the journal.

This is an open-access article distributed under the terms and conditions of the Creative Commons Attribution license which permits unrestricted use, distribution, and reproduction in any medium, provided the original work is properly cited. 